\title{
The fracture of ice on scales large and small: Arctic leads and wing cracks
}

\author{
E. M. Schulson AND W. D. Hibler, III \\ Thayer School of Engineering, Dartmouth College, Hanover, New Hampshire 03755, U.S.A.
}

\begin{abstract}
From observations and calculations of crack patterns in ice, it is suggested that a similar mechanism may account for cracking over a wide range of scales.
\end{abstract}

An important issue in ice mechanics is the relationship between small-scale and large-scale fracture. In materials studied in the laboratory, cracks nucleate on the scale of the grains (typically $1-10 \mathrm{~mm}$ in diameter), and then grow and link up into splits and faults the size of the specimen. In natural ice formations, such as glaciers and floating ice covers, cracks also form on the grain-size scale, but develop into large features such as crevasses and leads. The question, and one that also occurs in rock mechanics (Allègre and others, 1982) is: are the physical processes which occur on the different scales similar? This note focuses on leads within a sea-ice cover and argues that, when the stresses are appropriately scaled, the mechanisms yielding the large cracks may be similar to those operable within laboratory-sized samples.

Figure 1 shows an image of leads in the first-year ice cover on the Beaufort Sea. Banks Island is shown on the righthand side. The image is from 11 February 1983 and was obtained by satellite through the U.S. Air Force Defense Meteorological Satellite Program using infra-red sensors of $0.6 \mathrm{~km}$ resolution. The leads appear to form a pattern characterized by an alignment of sorts and, in

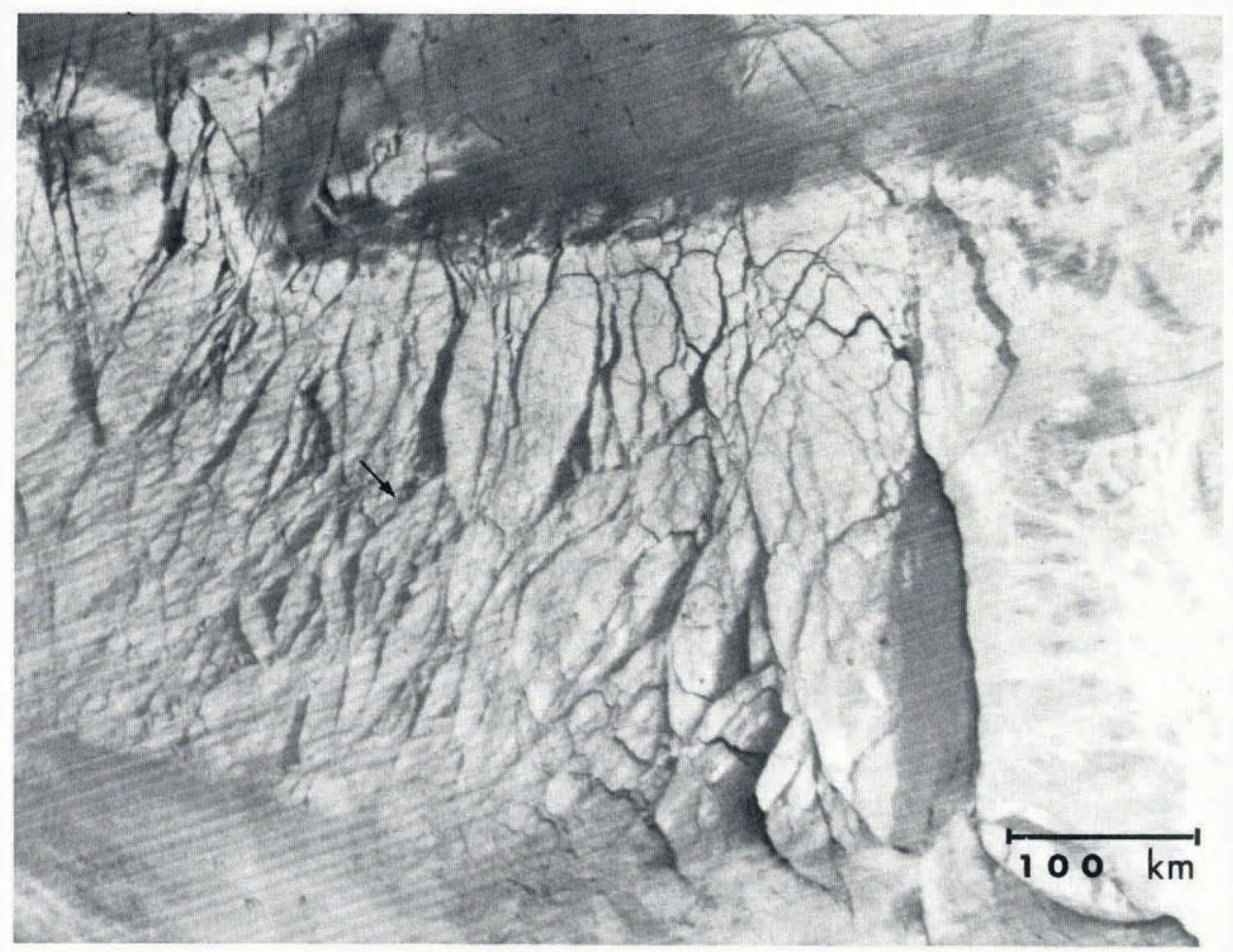

Fig. 1. Photograph of leads (dark features) in first-year sea ice within the Beaufort Sea. Banks Island is shown near the righthand side. Note the wing-like character of the feature marked with the arrow. The photograph was obtained on 11 February 1983 from a satellite using infra-red sensors of $0.6 \mathrm{~km}$ resolution. The image was obtained from film transparencies provided through the U.S. Air Force Defense Meteorological Satellite Program. (The transparencies are archived at NOAA and at the University of Colorado, CIRES/National Snow and Ice Data Center.) 

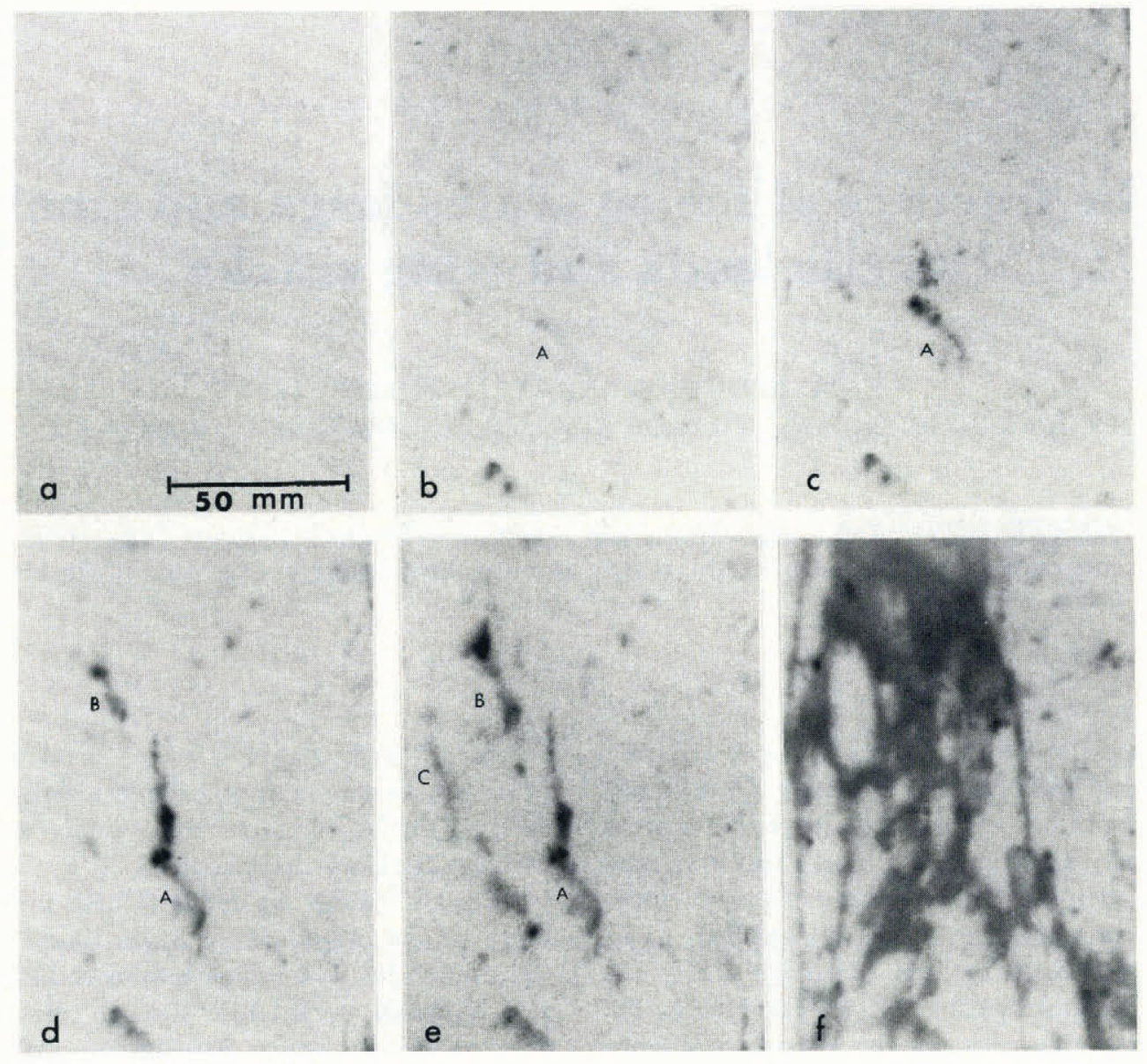

Fig. 2. Photographs of cracks in a specimen (shown in full) of fresh-water columnar ice loaded in the laboratory under compression (along the page) at $-10^{\circ} \mathrm{C}$ at $2 \times 10^{-2} \mathrm{~s}^{-1}$. The columnar grains are perpendicular to the face shown. The images were obtained from a high-speed film of the experiment and are displayed as negatives to reveal the cracks (dark features) more clearly. a. Zero stress; b. 2.1 MPa; c. 2.7 MPa; d. 4.0 MPa; e. 4.8MPa; f. 5.8 MPa. Crack A nucleated in (b) and developed extensions along the loading direction in (c)-(e), forming a wing crack. Wing cracks $B$ and $C$ formed later.

some areas, by steps or jogs inclined by about $45^{\circ}$ to the direction of alignment. The leads are wider at the tips of the steps, as though the ice on one side slid over the ice on the other side, wedging open the leads at their mouths. The arrow points to a particularly clear example.

Figure 2 shows a series of images of cracks in freshwater ice of columnar-shaped grains about $8 \mathrm{~mm}$ in diameter. The material was deformed under uniaxial compression in the laboratory at $-10^{\circ} \mathrm{C}$ at a strain rate of $2 \times 10^{-2} \mathrm{~s}^{-1}$. The images were obtained from a high-speed photographic record of the experiment and are rather blurry and grainy owing to the resolution of the system. The loading direction was perpendicular to the columnar axes (which were vertical in the parent ice sheet) and, in the images shown, is in the plane of the page parallel to the longer side of each image. The ice was initially free from cracks (Fig. 2a). Upon straining, a short crack (A; Fig. 2b), inclined about $45^{\circ}$ to the loading direction, formed at about one-third of the failure stress. As the stress increased, extensions (Fig. 2c) formed at both ends of the inclined crack, but along a direction parallel to the applied compressive load. These features developed in order to relieve the localized tensile stresses building at the crack tips as a result of sliding along the surface of the inclined crack. As the stresses increased further, the extensions lengthened in a macroscopically stable manner (Fig. 2ce), owing to further sliding along the surface of the parent crack. The inclined segment plus the two extensions is termed a wing crack, the growth of which occurs when the mode-I stress-intensity factor at its tips equals the fracture toughness of the material (Nemat-Nasser and Horii, 1982; Ashby and Hallam, 1986). Other wing cracks (B and C, Fig. 2e) formed at higher stresses and then propagated the full length of the specimen. The ice at this point contained several long cracks more or less aligned along the direction of loading. Failure occurred by splitting at a stress of around $5.8 \mathrm{MPa}$ and an axial strain of $7 \times 10^{-4}$. A quantitative analysis will be published elsewhere (Schulson and others, 1991b). Other examples of wing cracks and of interactions between them in small pieces of ice may be seen in Cannon and others (1990) and Schulson (1990).

In view of the similarity in the crack patterns, it is suggested that the kilometer-sized leads may be macroscopic wing cracks. If the large-scale lead pattern is analogous to the laboratory results, then the pattern probably developed under a far-field compressive stress state where the major component was more or less parallel 
to the direction of alignment. In other words, the leads shown in Figure 1 may have formed via a mechanism similar to the crack-sliding-wing-crack mechanism which led to the splits shown in Figure 2. This mechanism (Nemat-Nasser and Horii, 1982; Ashby and Hallam, 1986) is scale-independent.

As one test of the similarity, the stresses to form the leads can be estimated from two independent methods. First, we use wing-crack mechanics. Accordingly, from the analysis by Ashby and Hallam (1986) and from the application to ice by Schulson and others (1991a), a farfield uniaxial compressive stress of around $3 \mathrm{kPa}$ is needed to create the lead to which the arrow points in Figure 1. In the field, the applied far-field stress state is more likely to be biaxial than uniaxial, owing to the constraints imposed by the boundaries. In this case, the major principal stress at failure would be expected to be several times greater, based upon recent results of the effect of confinement on the failure strength of columnar ice (Smith and Schulson, 1991). In either case, the important elements in the calculation are the ratio of the extensions to the inclined step $(\approx 3: 1)$, the step length $(\approx 40 \mathrm{~km})$, the fracture toughness of the ice $\left(\approx 0.1 \mathrm{MPa} \mathrm{m}^{1 / 2} ;\right.$ Nixon and Schulson, 1988 ) and the sliding-friction coefficient for ice on ice $(\approx 0.5$; Jones and others, 1991). This stress is about three orders of magnitude lower than the failure stress of the laboratory specimen (recall 5.8 $\mathrm{MPa}$ for Figure 2), because the mechanism operates under a far-field compressive stress whose magnitude scales with the reciprocal square root of the length of the inclined step. For the sea ice, this step is about 1 million times longer than in the laboratory specimen.

The stresses which act in the ice cover can also be estimated from the solution of the equations of motion of a large-scale, sea-ice dynamics model (Ip and others, 1991). The input includes wind and water drag as well as steady ocean currents. Also, it includes the shape of the failure curve which was obtained from recent laboratory measurements (Smith, 1991; paper in preparation by T. R. Smith and E. M. Schulson) of the brittle compressive failure of columnar fresh-water and saline ice under biaxial loading. The implicit assumption is that information on failure curves from laboratory measurements may be a useful analog for a large-scale failure criterion. For 11 February 1983, the calculations indicate that a biaxial compressive stress state existed within the cover and that the major principal stress was $7-14 \mathrm{kPa}$. More detailed calculations and comparisons are under way (thesis in preparation by C.F. Ip). The two estimates are thus in reasonable accord.

It is recognized that the origin of the inclined crack must be addressed, for it is the length of this feature that underlies the scaling law. On the small scale, such cracks form along grain boundaries (Cannon and others, 1990) which are planes of weakness within the material. On the large scale the origin is not clear. Planes of weakness may also exist, but the origin will be different: it will reflect most probably a macroscopic structural feature which is peculiar to the larger body. It is also recognized that brittle behavior of ice is commonly associated with strain rates of around $10^{-3} \mathrm{~s}^{-1}$ and higher, based upon experiments in the laboratory. In the field, sea-ice sheets deform much more slowly, at the rate of approximately $1 \% \mathrm{~d}^{-1}$ $\left(\approx 10^{-7} \mathrm{~s}^{-1}\right)$. Ostensibly, therefore, it could appear erroneous to suggest the operation of a brittle-failure mechanism under conditions where ice may be thought to be ductile. Yet, the lead pattern is clearly the result of brittle behavior, followed by a divergent ice-velocity field which opens the cracks into leads. The resolution probably lies in a scale effect where the larger is an ice feature, the greater is its propensity to deform in a brittle as opposed to a ductile manner (Sanderson, 1988). Finally, it is recognized that the wing cracks illustrated in Figure 2 were generated within fresh-water ice, whereas the leads formed within a cover made from salt-water ice. Structural differences exist, the principal one being the incorporation of brinefilled pores within the sea ice. However, experiments (Smith, 1991) on saline ice prepared in the laboratory also show wing cracks in that material similar to those noted in Figure 2. They are less visible to high-speed photography owing to the opacity of the porous material, and for that reason are not illustrated here.

In suggesting that the wing-crack mechanism may account for the leads shown in Figure 1, it is not implied that a wing-crack-type process can account for all leads. Those formed under a far-field compressive stress which has a moderate to large degree of confinement probably originate through a different mechanism, because confinement to such levels suppresses crack sliding owing to the ice-to-ice friction (Schulson and others, 1991b). It is simply noted that in the case depicted in the figure the mechanism allows a reasonable explanation of the pattern. More work is needed to determine whether the model is a general one.

In conclusion, we have suggested that the process of lead formation within large sheets of sea ice loaded slowly under compression may be similar to the failure process within small specimens of ice loaded rapidly under compression. The concept is that the applicable stress states and crack characteristics may be similar across a wide range of scales. This note, we hope, will generate further discussion on this issue.

\section{ACKNOWLEDGEMENTS}

The authors would like to acknowledge Mr R. Weaver of the University of Colorado for bringing to their attention the satellite images and the wing-like cracks within them, as he did following a seminar by one of us (E. M. S.) Also, we would like to thank C.F. Ip for performing and analyzing the large-scale ice-model simulations. The work was funded by the U.S. Office of Naval Research through a University Research Initiative grant No. N00014-86-K0695.

\section{REFERENCES}

Allègre, C. J., J. L. Le Mouel and A. Provost. 1982. Scaling rules in rock fracture and possible implications for earthquake prediction. Nature, 297(21), 47-49.

Ashby, M.F. and S. D. Hallam. 1986. The failure of brittle solids containing small cracks under compressive stress states. Acta Metall., 34, 497-510.

Cannon, N.P., E. M. Schulson, T. R. Smith and H.J. 
Frost. 1990. Wing cracks and brittle compressive fracture. Acta Metall. Materialia, 38(10), 1955-1962.

Ip, C. F., W. D. Hibler, III and G. M. Flato. 1991. On the effect of rheology on seasonal sea-ice simulations. Ann. Glaciol., 15, 17-25.

Jones, D.E., F. E. Kennedy and E. M. Schulson. 1991. The kinetic friction of saline ice against itself at low sliding velocities. Ann. Glaciol., 15, 242-246.

Nemat-Nasser, S. and H. Horii. 1982. Compressioninduced nonplanar crack extension with application to splitting, exfoliation, and rockburst. F. Geophys. Res., 87(B8), 6805-6821.

Nixon, W.A. and E.M. Schulson. 1988. The fracture toughness of ice over a range of grain sizes. $\mathcal{7}$. Offshore Mech. Arct. Eng., 110(2), 192-196.

Sanderson, T.J.O. 1988. Ice mechanics: risks to offshore structures. London, Graham and Trotman.

Schulson, E. M. 1990. The brittle compressive fracture of ice. Acta Metall. Materialia, 38(10), 1963-1976.

Schulson, E. M., D. E. Jones and G. A. Kuehn. 1991a. The effect of confinement on the brittle compressive fracture of ice. Ann Glaciol., 15, 216-221.

Schulson, E. M., G. A. Kuehn, D. E. Jones and D. A. Fifolt. 1991b. The growth of wing cracks and the brittle compressive failure of ice. Acta Metall. Materialia, 39(11), 2651-2655.

Smith, T.R. 1991. The effect of stress state on the brittle compressive failure of columnar ice. (Ph.D. thesis, Dartmouth College.)

Smith, T.R. and E.M. Schulson. 1991. The brittle compressive failure of freshwater columnar ice under biaxial loading. Proceedings of O.M.A.E. Symposium on Ice Mechanics 1991, ASME, Vol. IV, 207-214.

The accuracy of references in the text and in this list is the responsibility of the authors, to whom queries should be addressed. 